\title{
Social Determinants of Change in Smoking Status over a 26-Year Follow up Period among Middle-Aged and Older Americans
}

\author{
Shervin Assari \\ Department of Family Medicine, Charles R Drew University of Medicine and Science, Los Angeles, CA, USA \\ Email: assari@umich.edu
}

How to cite this paper: Assari, S. (2021) Social Determinants of Change in Smoking Status over a 26-Year Follow up Period among Middle-Aged and Older Americans. Journal of Biosciences and Medicines, 9, 29-41.

https://doi.org/10.4236/jbm.2021.94003

Received: February 28, 2021

Accepted: April 12, 2021

Published: April 15, 2021

Copyright $\odot 2021$ by author(s) and Scientific Research Publishing Inc. This work is licensed under the Creative Commons Attribution International License (CC BY 4.0).

http://creativecommons.org/licenses/by/4.0/

\begin{abstract}
Educational attainment and income are among major socioeconomic status (SES) indicators that are inversely associated with cigarette smoking. Marginalization-related Diminished Returns (MDRs), however, are weaker protective effects of SES indicators for racial and ethnic minority groups compared to non-Hispanic White people. The aim is to test whether racial and ethnic differences exist in the effects of educational attainment and income on cigarette smoking of middle-aged and older American adults. This is a 26-year longitudinal study using data from the Health and Retirement Study (HRS), a nationally representative study of middle-aged and older adults in the US. A total number of 11,316 middle-aged and older adults (age $\geq 50$ ) were followed for up to 26 years. The independent variables were educational attainment and income. The dependent variables were always smoking and being quitters over the follow-up time. Age, gender, self-rated health, and chronic medical conditions were the covariates. Race/ethnicity was the moderator. Logistic regressions were used to analyze the data. Most participants were never smokers $(\mathrm{n}=7950)$, followed by quitters $(\mathrm{n}=1765)$, always smokers $(\mathrm{n}=$ 1272), and initiators $(\mathrm{n}=329)$. Overall, high educational attainment $(\mathrm{OR}=$ $0.92,95 \% \mathrm{CI}=0.90-0.95)$ and income $(\mathrm{OR}=0.99,95 \% \mathrm{CI}=0.99-0.99)$ reduced the odds of being always smoker. High educational attainment $(\mathrm{OR}=$ $1.05,95 \% \mathrm{CI}=1.02-1.08$ ) was associated with higher odds of being a quitter. Ethnicity, however, showed significant interactions with education on both outcomes suggesting that the effects of educational attainment on reducing the odds of always being a smoker $(\mathrm{OR}=1.24,95 \% \mathrm{CI}=1.14-1.35)$ and increasing the odds of quitting ( $\mathrm{OR}=0.84,95 \% \mathrm{CI}=0.75$ - 0.93) were smaller for Hispanics than non-Hispanics. In the United States, middle-aged and older Hispanic adults remain at high risk of smoking cigarettes despite high educational attainment. That is, high educational attainment may better help
\end{abstract}


non-Hispanic than Hispanic middle-aged and older adults to avoid cigarette smoking. As a result, we may observe a more than expected burden of tobacco use in middle class Hispanic middle-aged and older adults. Policymakers should not reduce racial and ethnic tobacco inequalities to SES gap, as ethnic tobacco disparities may persist in high SES levels as well.

\section{Keywords}

Smoking, Tobacco Use, Population Groups, Ethnic Groups, Race, Socioeconomic Position, Socioeconomic Status

\section{Introduction}

Although there has been some major decline in the prevalence of tobacco use in the US, cigarette smoking is still the leading preventable cause of morbidity and mortality in this country [1] [2] [3]. Each year, about 480,000 Americans die from illnesses that are due to tobacco use. In addition, more than 16 million Americans suffer from diseases that are caused by smoking [4]. As a result, tobacco costs the US about 300 billion USD each year, which is composed of $\$ 170$ and $\$ 156$ billion for direct and indirect costs, respectively [5].

The burden of tobacco use, however, is not randomly distributed in the US [6] [7] [8] [9] [10]. Despite the enormous progress that has been achieved in reducing the overall tobacco-related morbidity and mortality, tobacco use has shown a considerable shift from mainstream to a concentrated public health challenge that mainly affects marginalized populations defined by socioeconomic status (SES), race, and ethnicity [11]. Such social disparities threaten the progress that the US has already made in its tobacco control [11].

Racial and ethnic minorities [6] [7] [8] [9] [10] and low SES individuals [12] [13] [14] bear the vast majority of tobacco burden in the US. Some evidence suggests that SES disparities in tobacco use have increased [14] [15] [16]. Between 1966 and 2015, cigarette smoking declined by 83\% in American adults with a college degree. At the same time, the decline was only $40 \%$ for Americans who did not have a high school diploma [11]. A large proportion of tobacco disparities are not all due to individuals' choices but social processes that place marginalized groups at higher risk of exposure to tobacco. For example, racial, ethnic, and low SES individuals are targets of predatory tobacco marketing [17] [18] [19]. Low SES individuals, as well as racial and ethnic minorities, are more frequently exposed to environmental risk factors of tobacco use including but not limited to retail display, coupon, discount, and point-of-sale advertisement [20]. The result is their increasing vulnerability of racial/ethnic and low SES individuals [21], which is characterized by a more rapid transition from initiation to undesired outcomes, in part due to low access to cessation programs [8] [22] [23].

Recent research on Marginalization-related Diminished Returns (MDRs) has 
proposed a new mechanism for racial and ethnic health disparities in the US [24] [25]. That is, SES indicators do not similarly protect various ethnic groups, and racial and ethnic minorities tend to remain at a higher risk of poor health outcomes [24] [25]. This model proposes that: 1) racial/ethnic health inequalities in tobacco burden are not merely and exclusively due to SES gaps but also due to smaller effects of SES indicators for minority populations, and 2) the racial and ethnic health disparities persist and may even widen at high SES levels. This model emphasizes a need to explore the joint and multiplicative effects of race/ethnicity and SES indicators, which allows for the differential return of SES in terms of health outcomes. Finally, this model suggests that the elimination of racial and ethnic health disparities is beyond equalizing SES. The model suggests that a real solution to health disparities requires bold social and economic policies that affect qualitatively different life conditions of racial and ethnic groups [24] [25].

Research has shown that MDRs may also apply to tobacco use of youth [26] and adults [27] [28] [29]. According to this literature, at least some of the racial/ethnic tobacco use disparities are because of "weaker than expected" protective effects of SES indicators on tobacco use for racial, ethnic, and sexual minority populations [27] [28] [29]. Such MDRs are shown for education [30], employment [27], and parental education 26, and has been found for various products such as traditional cigarette as well as e-cigarette [30]. Although MDRs are shown to increase tobacco use of youth [26] and adults [27] [28] [29], the same is not shown for middle-aged and older American adults. Similar patterns (MDRs), however, are shown for other substances such as alcohol [28] [31] and even other behaviors such as diet [32] and exercise [33]. All these risk profiles result in a more than expected rate of chronic diseases [34], such as asthma [35] and COPD [36] and also hospitalization [37] and mortality in middle-class ethnic minority people. Given the systemic nature of the observed, MDRs are attributed to societal inequalities rather than groups' or individuals' characteristics or behaviors. MDRs are argued to be a side effect of the marginalization of racial and minority populations [34] [35].

\section{Aim}

This study tested racial and ethnic variation in the effects of two SES indicators, namely educational attainment, and income, on cigarette smoking in a nationally representative sample of middle-aged and older American adults. We expected smaller protective effects of educational attainment and income for Blacks and Hispanics than Non-Hispanic Whites.

\section{Methods}

\subsection{Design and Setting}

The Health and Retirement Study (HRS) is a state-of-the-art long-term longitudinal study with biannual observations from 1992 to 2016. The HRS has recruited a nationally representative sample of American middle-aged and older 
adults over the age of 50. Detailed methodological information regarding the study design, measures, sample, and sampling is available elsewhere [38].

\subsection{Ethics Statement}

The HRS study protocol was evaluated and approved by the University of Michigan Institutional Review Board. Participants signed informed consent. All data were collected, restored, managed, and analyzed anonymously.

\subsection{Participants and Sampling}

This study only included the core primary sample of the HRS that was recruited in 1992. Participants were born between 1931 and 1941. The HRS sampling strategy was a national area probability sample of US households.

\subsection{Analytical Sample}

The current study included individuals who were 50+ years old and self-identified as White or Black. Both Hispanic and non-Hispanic people were enrolled in our analysis. This sample included 11,316 . The entirety of this sample was included in our analysis regardless of the duration of the follow up.

\subsection{Data Collection}

Extensive data on demographic, SES, social, psychological, behavioral, and health information were collected. Data were collected from participants and their spouses. Data were collected on a biannual basis. Data collection was either through standard questionnaires that were completed wither in a telephone or a face-to-face interview. For the individuals who were not available, proxy interviews were used.

\section{Measures}

\subsection{Demographic Factors}

Age and gender were demographic factors. Age was a continuous measure recorded in years. Gender was a dichotomous variable: male $=1$, female $=0$. Age and gender were measured in 1992.

\subsection{Socioeconomic Status (SES) Indicators}

Educational attainment and income were the SES indicators. Education was a continuous measure recorded in years of schooling. Income was a continuous variable in USD 1000. Both SES indicators were measured at baseline (1992).

\subsection{Depressive Symptoms}

The eight-item Center for Epidemiologic Studies Depression scale (CES-D) was used to measure depressive symptoms. The CES-D scale is a reliable and validated measure of the level of depressive symptomatology over the past week [39] [40] [41]. We used the baseline CES-D score measured in 1992, with a higher 
score indicating more depressive symptomatology.

\subsection{Self-Rated Health (SRH)}

A conventional single-item measure of SRH was used. Participants reported their health was excellent, very good, good, fair, or poor. SRH was operationalized as a continuous variable ranging between 1 and 5 . A higher score indicated worse health. Research has repeatedly demonstrated high validity and reliability of SRH as a predictor of mortality risk [42]. We used the baseline SRH measured in 1992.

\subsection{Chronic Medical Conditions (CMCs)}

A single variable was used that reflected the number (count) of various chronic medical conditions, including diabetes mellitus, heart disease, emphysema/asthma, stroke, cancer, hypertension, arthritis, and psychiatric conditions. Participants were asked if they were ever told by a doctor that they have any of these conditions. This variable had a range of 0 to 8 , with a higher score reflecting multimorbidity.

\subsection{Smoking Classes}

Using data from smoking data across all waves, we generated four clusters of individuals. Always smokers, as people who reported current smoking status at all waves that they participated in. Never smokers, as individuals who reported non-smoking status at all waves that they participated. Quitters were composed of people who started the HRS cohort as a smoker but discontinued smoking at least at one future observation. Finally, initiators were composed of people who started the HRS as non-smokers but became a smoker at least in one observation in the next waves.

\subsection{Data Analysis}

We analyzed the HRS data using SPSS 23 (IBM Corp, Armonk, New York, USA). We used Taylor series estimation to calculate the variance of our study variables using survey design variables such as HRS survey weight and PSU that reflected clustering, stratification, and non-response. As a result of applying the HRS weight, the results of the current analysis are generalizable to the US general population of middle-aged and older adults. For our univariate analyses, we reported means and frequencies. We then ruled out the collinearities between race, ethnicity, educational attainment, income, and covariates. We did not have missing data simply because two waves were enough for the definition of our smoking trajectories. For multivariable analysis, we applied binary logistic regressions with smokers (vs. never smokers), initiators (vs. never smokers), and quitters (vs. always smokers) as outcomes. We ran three series of models without (Model 1) and with (Model 2) our four statistical interaction terms between race/ethnicity and SES indicators (educational attainment and income). As both 
SES indicators were operationalized as a resource rather than risk, we expected their protective effects to be reflected by ORs less than 1 . We, however, expected ORs larger than 1 for the interaction terms, suggesting that the associations between SES indicators and smoking outcomes would be smaller for Blacks and Hispanics.

\section{Results}

\subsection{Descriptive Statistics}

In this study, 25,654 American adults were followed overtime for up to 26 years. Participants were either Non-Hispanic, Hispanic, White, or Black. Table 1 summarizes the descriptive statistics of the sample (Table 1).

Table 1 also compared the following study groups: 1) Always Smokers, 2) Initiators, 3) Quitters, and 4) Never Smokers. These groups differed in race, ethnicity, gender, education, income, SRH, CMCs, and depressive symptoms.

\subsection{Multivariable Models}

\subsubsection{Outcome: Smoking}

Table 2 summarizes the results of two pooled sample logistic regression models

Table 1. Descriptive statistics in the overall sample.

\begin{tabular}{|c|c|c|c|c|c|c|c|c|c|c|}
\hline & \multicolumn{2}{|c|}{$\begin{array}{l}\text { Always } \\
\text { Smokers }\end{array}$} & \multicolumn{2}{|c|}{ Initiators } & \multicolumn{2}{|c|}{ Quitters } & \multicolumn{2}{|c|}{$\begin{array}{c}\text { Never } \\
\text { Smokers }\end{array}$} & \multicolumn{2}{|c|}{ All } \\
\hline & $\mathbf{N}$ & $\%$ & $\mathrm{n}$ & $\%$ & $\mathbf{n}$ & $\%$ & $\mathrm{n}$ & $\%$ & $\mathbf{n}$ & $\%$ \\
\hline \multicolumn{11}{|l|}{ Race $^{*}$} \\
\hline White & 6377 & 83.4 & 254 & 80.4 & 1367 & 80.1 & 987 & 81.0 & 8985 & 82.5 \\
\hline Black & 1268 & 16.6 & 62 & 19.6 & 339 & 19.9 & 232 & 19.0 & 1901 & 17.5 \\
\hline \multicolumn{11}{|l|}{ Ethnicity ${ }^{\star}$} \\
\hline Non-Hispanic & 7181 & 90.4 & 290 & 88.1 & 1601 & 90.8 & 1186 & 93.5 & 10258 & 90.7 \\
\hline Hispanic & 764 & 9.6 & 39 & 11.9 & 163 & 9.2 & 82 & 6.5 & 1048 & 9.3 \\
\hline \multicolumn{11}{|l|}{ Gender ${ }^{*}$} \\
\hline Women & 4060 & 51.1 & 122 & 37.1 & 863 & 48.9 & 557 & 43.8 & 5602 & 49.5 \\
\hline \multirow[t]{2}{*}{ Men } & 3890 & 48.9 & 207 & 62.9 & 902 & 51.1 & 715 & 56.2 & 5714 & 50.5 \\
\hline & Mean & $\mathrm{SD}$ & Mean & SD & Mean & SD & Mean & SD & Mean & SD \\
\hline Age & 56.65 & 4.58 & 55.91 & 4.03 & 55.86 & 4.14 & 56.17 & 4.40 & 56.46 & 4.49 \\
\hline Education $^{*}$ & 12.19 & 3.35 & 11.73 & 3.33 & 11.55 & 3.16 & 11.19 & 2.99 & 11.97 & 3.30 \\
\hline Income $^{*}$ & 50.04 & 53.72 & 45.20 & 50.38 & 38.74 & 37.48 & 34.64 & 42.00 & 46.40 & 50.52 \\
\hline Self-Rated Health ${ }^{*}$ & 1.17 & 1.85 & 1.51 & 2.23 & 1.71 & 2.31 & 1.75 & 2.16 & 1.33 & 1.99 \\
\hline $\begin{array}{c}\text { Chronic Medical } \\
\text { Conditions }^{*}\end{array}$ & 2.52 & 1.19 & 2.83 & 1.23 & 2.71 & 1.18 & 3.01 & 1.26 & 2.62 & 1.21 \\
\hline Depressive Symptoms* & 1.08 & 1.10 & 1.05 & 1.23 & 1.03 & 1.13 & 1.32 & 1.32 & 1.10 & 1.14 \\
\hline
\end{tabular}

${ }^{\star} \mathrm{P}<0.05$ for comparison of always smokers, initiators, quitters, and never smokers 
Table 2. Summary of logistic regression of always smoking over the follow-up period.

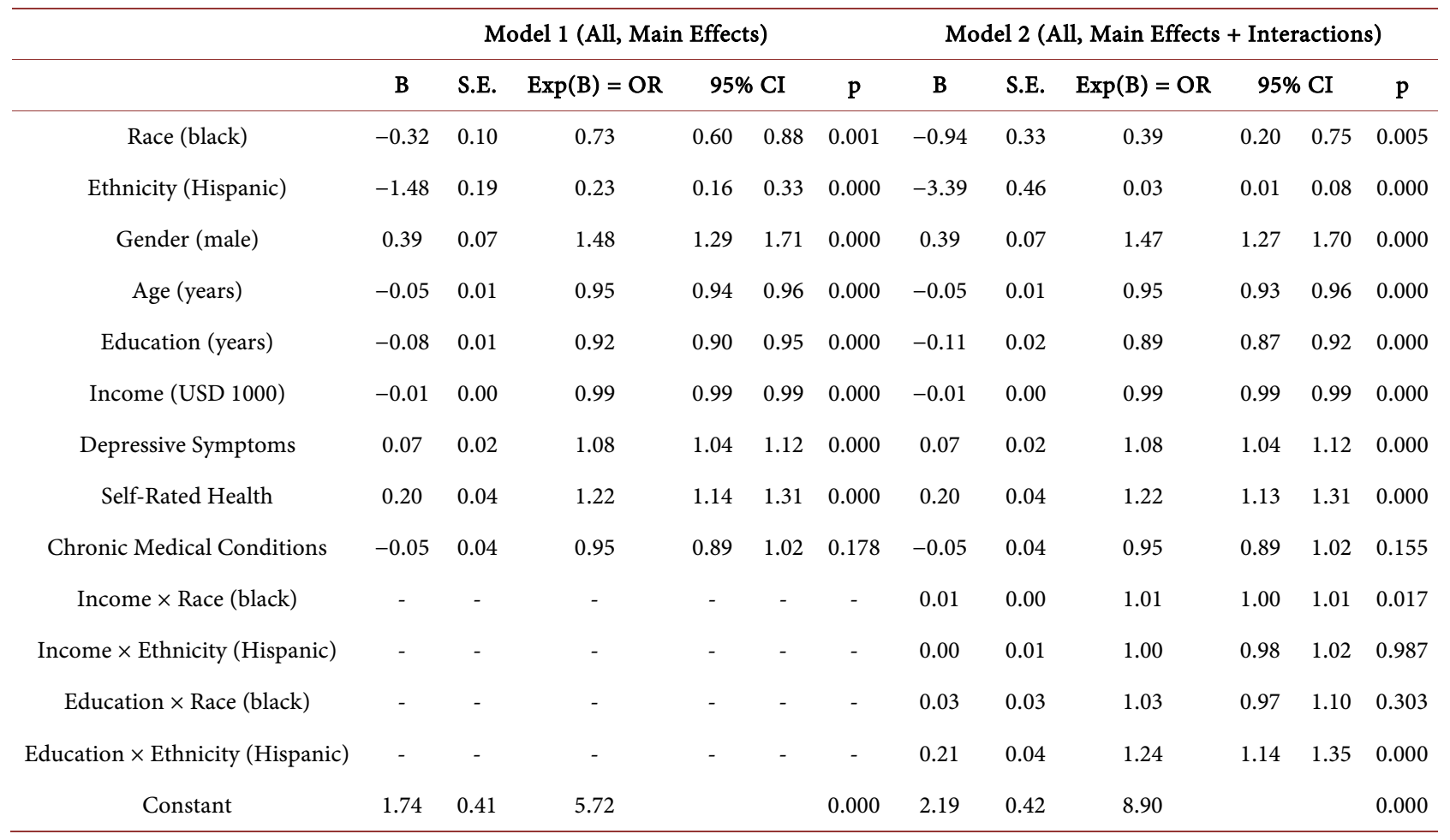

Notes: CI: Confidence Interval; SE: Standard Error; OR: Odds Ratio.

with education and income as the predictor/independent variables and always smoking over the follow-up period as the outcome/dependent variable. Model 1 had the main effects of educational attainment, income, race, ethnicity, and covariates, while Model 2 also included four interaction terms between race/ethnicity and education and income.

Based on Model 1, overall, high education $(\mathrm{OR}=0.92,95 \% \mathrm{CI}=0.90-0.95)$ and income $(\mathrm{OR}=0.99,95 \% \mathrm{CI}=0.99-0.99)$ were associated with lower odds of always smoking. Model 2 revealed an interaction between ethnicity with education $(\mathrm{OR}=1.24,95 \% \mathrm{CI}=1.14-1.35)$ on odds of always smoking, suggesting that the protective effect of high education against always smoking was smaller for Hispanics than Non-Hispanics (Table 2).

\subsubsection{Outcome: Quitting}

Table 3 presents the summary of the results of two pooled-sample logistic regression models with education and income as the independent variables and quitting over the follow up as the dependent variable. Model 3 only entered the main effects, while Model 4 also added four interaction terms. Based on Model 1 , high education $(\mathrm{OR}=1.05,95 \% \mathrm{CI}=1.02-1.08)$ increased the odds of quitting. Model 2 showed an interaction between ethnicity and education on odds of quitting ( $\mathrm{OR}=0.84,95 \% \mathrm{CI}=0.75$ - 0.93), suggesting that the effect of education on odds of quitting was smaller for Hispanics than Non-Hispanics (Table $3)$. 
Table 3. Summary of logistic regression on the effect of education and income on quitting over the follow-up period.

\begin{tabular}{ccccccccccccc}
\hline & \multicolumn{4}{c}{ Model 3 (All, Main Effects) } & \multicolumn{4}{c}{ Model 4 (All, Main Effects + Interactions) } \\
\hline & B & S.E. & Exp(B)= OR & 95\% CI & p & B & S.E. & Exp(B) $=$ OR & $95 \%$ CI & P \\
\hline Race (black) & 0.29 & 0.11 & 1.34 & 1.08 & 1.65 & 0.007 & 0.41 & 0.39 & 1.51 & 0.69 & 3.26 & 0.300 \\
Ethnicity (Hispanic) & 0.90 & 0.20 & 2.45 & 1.66 & 3.61 & 0.000 & 2.39 & 0.56 & 10.88 & 3.64 & 32.51 & 0.000 \\
Gender (male) & -0.14 & 0.08 & 0.87 & 0.74 & 1.02 & 0.089 & -0.14 & 0.08 & 0.87 & 0.74 & 1.03 & 0.107 \\
Age (years) & 0.01 & 0.01 & 1.01 & 1.00 & 1.03 & 0.064 & 0.01 & 0.01 & 1.01 & 1.00 & 1.03 & 0.064 \\
Education (years) & 0.05 & 0.02 & 1.05 & 1.02 & 1.08 & 0.003 & 0.06 & 0.02 & 1.07 & 1.03 & 1.11 & 0.001 \\
Income (USD 1000) & 0.00 & 0.00 & 1.00 & 1.00 & 1.00 & 0.366 & 0.00 & 0.00 & 1.00 & 1.00 & 1.00 & 0.229 \\
Depressive Symptoms & 0.02 & 0.02 & 1.02 & 0.98 & 1.06 & 0.252 & 0.02 & 0.02 & 1.02 & 0.98 & 1.07 & 0.244 \\
Self-Rated Health & -0.09 & 0.04 & 0.91 & 0.84 & 0.99 & 0.033 & -0.09 & 0.04 & 0.91 & 0.84 & 0.99 & 0.028 \\
Chronic Medical Conditions & -0.11 & 0.04 & 0.89 & 0.82 & 0.97 & 0.005 & -0.11 & 0.04 & 0.90 & 0.83 & 0.97 & 0.007 \\
Income $\times$ Race (black) & - & - & - & - & - & - & 0.00 & 0.00 & 1.00 & 0.99 & 1.00 & 0.100 \\
Income $\times$ Ethnicity (Hispanic) & - & - & - & - & - & - & 0.01 & 0.01 & 1.01 & 0.99 & 1.02 & 0.382 \\
Education $\times$ Race (black) & - & - & - & - & - & - & 0.00 & 0.04 & 1.00 & 0.94 & 1.08 & 0.891 \\
Education $\times$ Ethnicity (Hispanic) & - & - & - & - & - & - & -0.18 & 0.06 & 0.84 & 0.75 & 0.93 & 0.002 \\
Constant & -0.53 & 0.48 & 0.59 & & & 0.271 & -0.76 & 0.50 & 0.47 & & 0.132 \\
\hline
\end{tabular}

Notes: CI: Confidence Interval; SE: Standard Error; OR: Odds Ratio.

\section{Discussion}

Overall, high education and income were associated with lower odds of being a smoker, and high educational attainment was associated with increased odds of quitting smoking over the 26 years of follow up. We, however, found a significant interaction between race and educational attainment, suggesting that high education has a weaker inverse association with smoking for Hispanic than Non-Hispanic Whites. Similarly, education had a weaker positive association with the future chance of quitting for Hispanic than Non-Hispanic Whites.

Previous studies have shown that due to MDRs, high SES (e.g., education, income, and employment), Blacks and Hispanics remain at an increased risk of substance use [28] [29] [31] [43]. This is due to weaker than expected effects of education, income, and employment for Blacks compared to Whites [28] [29] [31] [43]. Similar patterns are shown for the effects of SES on obesity [44], depression [45], anxiety [46], self-rated health [47], and chronic disease [48] for Blacks and Hispanics.

One of the proposed mechanisms by which the risk of tobacco use stays high is a lower quality of education in predominantly Black and Hispanic areas. Another explanation may be structural factors such as residential segregation. Finally, predatory marketing practices may have a role. We already know that the tobacco industry specifically targets racial/ethnic and low SES areas, which creates disparity [17] [18] [19]. Future research is needed to understand the type of policies and practices that contribute to MDRs-related disparities. Predatory 
marketing and advertising may increase the vulnerability of low SES, Blacks, and Hispanics for tobacco use, a pattern that may explain why smoking is more common among high Hispanic individuals, relative to high SES non-Hispanic Whites. If confirmed by future research, there is a need to introduce more restrictive marketing policies that reduce such predatory marketing. Such strategies would require banning point-of-sale advertisement and flavoring and specially focusing on disadvantaged areas that have a high concentration of Black and Hispanic populations. Research is also needed on the effects of restricting predatory marketing as a strategy to eliminate tobacco use disparities by race, ethnicity, and SES, at least those that are generated by MDRs of SES [49].

\section{Implications}

We argue that the high tobacco risk of highly educated ethnic minorities should be alarming for the FDA. Elimination of tobacco-related disparities in racial, ethnic, and marginalized people is a strategic priority for FDA and NIH. The results are relevant to the "understanding of why people become susceptible to using tobacco products," which is one of the FDA's research priorities.

The observation that highly educated Hispanic are at risk of tobacco use and have a lower chance of smoking than their White counterparts has some policy and public health implications and may help the FDA set priorities to tackle health disparities. Our finding is suggestive that tobacco regulation policies should consider the intersection of race, ethnicity, and SES. Effective policies that can reduce tobacco-related disparities are those that go beyond addressing racial/ethnic and SES gaps by addressing the MDRs-related disparities (those due to weaker effects of SES indicators for the members of the racial and ethnic minorities.

\section{Limitations}

The current study is not free of methodological limitations. As the sample size was different across race and ethnic groups, we did not perform race/ethnic-specific models. Such models would not be comparable, given the unequal size across race and ethnic groups. Other SES markers, such as wealth, employment, and area-level SES, were not included in this study. This study did not measure some health measured that could confound the link between SES and tobacco use. Mental health problems may have a major role. Finally, individuals lived under unequal tobacco policies that were not studied. Despite these limitations, we believe the results derived from this study still make a unique expansion of the existing literature on racial and ethnic tobacco disparities in middle-aged and older adults.

\section{Conclusion}

In the United States, Hispanic ethnicity may limit the health effect of an SES indicator such as education on smoking and quit. While education helps individu- 
als to avoid high-risk behaviors such as smoking as well as increase their chance of quitting, these effects depend on ethnicity. While the more privileged groups (non-Hispanics) gain the most from their educational attainment, the least-privileged groups (Hispanics) gain the least.

\section{Author Contributions}

The paper only has one author.

\section{Funding}

The research reported in this publication was supported by the National Cancer Institute of the National Institutes of Health (NIH) and FDA Center for Tobacco Products (CTP) under Award Number U54CA229974. The content is solely the responsibility of the authors and does not necessarily represent the official views of the NIH or the Food and Drug Administration. Shervin Assari is also funded by the NIH under Awards U54MD008149, R25 MD007610, U54MD007598, and U54 TR001627, and CA201415-02.

\section{Conflicts of Interest}

The author declares no conflict of interest.

\section{References}

[1] McCarthy, M. (2014) Smoking Remains Leading Cause of Premature Death in US. BMJ, 348, g396. https://doi.org/10.1136/bmj.g396

[2] Samet, J.M. (2013) Tobacco Smoking: The Leading Cause of Preventable Disease Worldwide. Thoracic Surgery Clinics, 23, 103-112. https://doi.org/10.1016/j.thorsurg.2013.01.009

[3] Novick, L.F. (2000) Smoking Is the Leading Preventable Cause of Death and Disability in the United States. Journal of Public Health Management and Practice, 6, 6.

[4] CDC (2019) Smoking \& Tobacco Use. Fast Facts.

[5] CDC. Economic Trends in Tobacco.

[6] Ellickson, P.L., Orlando, M., Tucker, J.S., Klein, D.J. (2004) From Adolescence to Young Adulthood: Racial/Ethnic Disparities in Smoking. American Journal of Public Health, 94, 293-299. https://doi.org/10.2105/AJPH.94.2.293

[7] Centers for Disease C Prevention (2010) Racial Disparities in Smoking-Attributable Mortality and Years of Potential Life Lost-Missouri, 2003-2007. Morbidity and Mortality Weekly Report, 59, 1518-1522.

[8] Trinidad, D.R., Perez-Stable, E.J., White, M.M., Emery, S.L. and Messer, K. (2011) A Nationwide Analysis of US Racial/Ethnic Disparities in Smoking Behaviors, Smoking Cessation, and Cessation-Related Factors. American Journal of Public Health, 101, 699-706. https://doi.org/10.2105/AJPH.2010.191668

[9] Soulakova, J.N., Huang, H. and Crockett, L.J. (2015) Racial/Ethnic Disparities in Consistent Reporting of Smoking-Related Behaviors. Journal of Addictive Behaviors, Therapy \& Rehabilitation, 4. https://doi.org/10.4172/2324-9005.1000147

[10] Blumenthal, D.S. (2017) Racial and Ethnic Disparities in Smoking Prevalence in Israel and the United States: Progress to Date and Prospects for the Future. Israel 
Journal of Health Policy Research, 6, 51. https://doi.org/10.1186/s13584-017-0177-9

[11] Drope, J., Liber, A.C., Cahn, Z., et al. (2018) Who's Still Smoking? Disparities in Adult Cigarette Smoking Prevalence in the United States. CA: A Cancer Journal for Clinicians, 68, 106-115. https://doi.org/10.3322/caac.21444

[12] Laveist, T.A., Thorpe, R.J., Mance, G.A. and Jackson, J. (2007) Overcoming Confounding of Race with Socio-Economic Status and Segregation to Explore Race Disparities in Smoking. Addiction, 102, 65-70.

https://doi.org/10.1111/j.1360-0443.2007.01956.x

[13] Reid, J.L., Hammond, D. and Driezen, P. (2010) Socio-Economic Status and Smoking in Canada, 1999-2006: Has There Been Any Progress on Disparities in Tobacco Use? Canadian Journal of Public Health, 101, 73-78. https://doi.org/10.1007/BF03405567

[14] Zhang, X., Martinez-Donate, A.P. and Jones, N.R. (2013) Educational Disparities in Home Smoking Bans among Households with Underage Children in the United States: Can Tobacco Control Policies Help to Narrow the Gap? Nicotine \& Tobacco Research, 15, 1978-1987. https://doi.org/10.1093/ntr/ntt090

[15] Reimer, R.A., Gerrard, M. and Gibbons, F.X. (2010) Racial Disparities in Smoking Knowledge among Current Smokers: Data from the Health Information National Trends Surveys. Psychology \& Health, 25, 943-959. https://doi.org/10.1080/08870440902935913

[16] Rock, V.J., Davis, S.P., Thorne, S.L., Asman, K.J. and Caraballo, R.S. (2010) Menthol Cigarette Use among Racial and Ethnic Groups in the United States, 2004-2008. Nicotine \& Tobacco Research, 12, S117-S124. https://doi.org/10.1093/ntr/ntq204

[17] Terry-McElrath, Y.M., Wakefield, M.A., Emery, S., et al. (2007) State Anti-Tobacco Advertising and Smoking Outcomes by Gender and Race/Ethnicity. Ethnicity \& Health, 12, 339-362. https://doi.org/10.1080/13557850701300723

[18] Keeler, C., Max, W., Yerger, V., Yao, T., Ong, M.K. and Sung, H.Y. (2017) The Association of Menthol Cigarette Use with Quit Attempts, Successful Cessation, and Intention to Quit across Racial/Ethnic Groups in the United States. Nicotine \& Tobacco Research, 19, 1450-1464. https://doi.org/10.1093/ntr/ntw215

[19] Giovenco, D.P., Spillane, T.E. and Merizier, J.M. (2018) Neighborhood Differences in Alternative Tobacco Product Availability and Advertising in New York City: Implications for Health Disparities. Nicotine \& Tobacco Research, 21, 896-902.

https://doi.org/10.1093/ntr/nty244

[20] Anderson, S.J. (2011) Marketing of Menthol Cigarettes and Consumer Perceptions: A Review of Tobacco Industry Documents. Tobacco Control, 20, ii20-ii28. https://doi.org/10.1136/tc.2010.041939

[21] Greaves, L. and Hemsing, N. (2009) Women and Tobacco Control Policies: Social-Structural and Psychosocial Contributions to Vulnerability to Tobacco Use and Exposure. Drug and Alcohol Dependence, 104, S121-S130. https://doi.org/10.1016/j.drugalcdep.2009.05.001

[22] Cokkinides, V.E., Halpern, M.T., Barbeau, E.M., Ward, E. and Thun, M.J. (2008) Racial and Ethnic Disparities in Smoking-Cessation Interventions: Analysis of the 2005 National Health Interview Survey. American Journal of Preventive Medicine, 34, 404-412. https://doi.org/10.1016/j.amepre.2008.02.003

[23] Tran, S.T., Rosenberg, K.D. and Carlson, N.E. (2010) Racial/Ethnic Disparities in the Receipt of Smoking Cessation Interventions during Prenatal Care. Maternal and Child Health Journal, 14, 901-909. https://doi.org/10.1007/s10995-009-0522-x

[24] Assari, S. (2018) Health Disparities Due to Diminished Return among Black Amer- 
icans: Public Policy Solutions. Social Issues and Policy Review, 12, 112-145. https://doi.org/10.1111/sipr.12042

[25] Assari, S. (2017) Unequal Gain of Equal Resources across Racial Groups. International Journal of Health Policy and Management, 7, 1-9. https://doi.org/10.15171/ijhpm.2017.90

[26] Assari, S.B.M. and Caldwell, C.H. (2020) Parental Educational Attainment and Youth Outcomes: Hispanics' Diminished Returns. JAMA Network Open.

[27] Shervin, A. and Ritesh, M. (2019) Diminished Return of Employment on Ever Smoking among Hispanic Whites in Los Angeles. Health Equity, 3, 138-144. https://doi.org/10.1089/heq.2018.0070

[28] Assari, S., Farokhnia, M. and Mistry, R. (2019) Education Attainment and Alcohol Binge Drinking: Diminished Returns of Hispanics in Los Angeles. Behavioral Science (Basel), 9, 9. https://doi.org/10.3390/bs9010009

[29] Assari, S. and Mistry, R. (2018) Educational Attainment and Smoking Status in a National Sample of American Adults; Evidence for the Blacks' Diminished Return. International Journal of Environmental Research and Public Health, 15, 763. https://doi.org/10.3390/ijerph15040763

[30] Assari, S., Mistry, R. and Bazargan, M. (2020) Race, Educational Attainment, and E-Cigarette Use. Journal of Medical Research and Innovation, 4, e000185. https://doi.org/10.32892/jmri.185

[31] Assari, S. and Lankarani, M.M. (2016) Education and Alcohol Consumption among Older Americans; Black-White Differences. Frontiers in Public Health, 4, 67. https://doi.org/10.3389/fpubh.2016.00067

[32] Assari, S. and Lankarani, M. (2018) Educational Attainment Promotes Fruit and Vegetable Intake for Whites but Not Blacks. J, 1, 29-41.

https://doi.org/10.3390/j1010005

[33] Assari, S. (2019) Educational Attainment and Exercise Frequency in American Women; Blacks' Diminished Returns. Women's Health Bulletin, 6, e87413. https://doi.org/10.5812/whb.87413

[34] Assari, S. (2018) The Benefits of Higher Income in Protecting against Chronic Medical Conditions Are Smaller for African Americans than Whites. Healthcare (Basel), 6, 2. https://doi.org/10.3390/healthcare6010002

[35] Assari, S. and Moghani Lankarani, M. (2018) Poverty Status and Childhood Asthma in White and Black Families: National Survey of Children's Health. Healthcare (Basel), 6, 62. https://doi.org/10.3390/healthcare6020062

[36] Assari, S.C.H. and Bazargan, M. (2019) High Education Level Protects European Americans But Not African Americans against Chronic Obstructive Pulmonary Disease: National Health Interview Survey. International Journal of Biomedical Engineering and Clinical Science, 5, 23-30. https://doi.org/10.11648/j.ijbecs.20190502.12

[37] Assari, S. and Bazargan, M. (2019) Minorities' Diminished Returns of Educational Attainment on Hospitalization Risk: National Health Interview Survey (NHIS). Hospital Practices and Research, 4, 86-91. https://doi.org/10.15171/hpr.2019.17

[38] Sonnega, A., Faul, J.D., Ofstedal, M.B., Langa, K.M., Phillips, J.W. and Weir, D.R. (2014) Cohort Profile: The Health and Retirement Study (HRS). International Journal of Epidemiology, 43, 576-585. https://doi.org/10.1093/ije/dyu067

[39] Radloff, L.S. (1977) The CES-D Scale: A Self-Report Depression Scale for Research in the General Population. Applied Psychological Measurement, 1, 385-401. 
https://doi.org/10.1177/014662167700100306

[40] Radloff, L.S. and Rae, D.S. (1979) Susceptibility and Precipitating Factors in Depression: Sex Differences and Similarities. Journal of Abnormal Psychology, 88, 174-181. https://doi.org/10.1037/0021-843X.88.2.174

[41] Radloff, L.S. (1991) The Use of the Center for Epidemiologic Studies Depression Scale in Adolescents and Young Adults. Journal of Youth and Adolescence, 20, 149-166. https://doi.org/10.1007/BF01537606

[42] Idler, E.L. and Benyamini, Y. (1997) Self-Rated Health and Mortality: A Review of Twenty-Seven Community Studies. Journal of Health and Social Behavior, 38, 21-37. https://doi.org/10.2307/2955359

[43] Assari, S. and Mistry, R. (2018) Erratum: Assari, S.; Mistry, R. Educational Attainment and Smoking Status in a National Sample of American Adults; Evidence for the Blacks' Diminished Return. Int. J. Environ. Res. Public Health 2018, 15, 763. International Journal of Environmental Research and Public Health, 15, 2084. https://doi.org/10.3390/ijerph15102084

[44] Assari, S., Thomas, A., Caldwell, C.H. and Mincy, R.B. (2018) Blacks' Diminished Health Return of Family Structure and Socioeconomic Status; 15 Years of Follow-Up of a National Urban Sample of Youth. Journal of Urban Health, 95, 21-35. https://doi.org/10.1007/s11524-017-0217-3

[45] Assari, S. and Caldwell, C.H. (2018) High Risk of Depression in High-Income African American Boys. Journal of Racial and Ethnic Health Disparities, 5, 808-819. https://doi.org/10.1007/s40615-017-0426-1

[46] Assari, S., Caldwell, C.H. and Zimmerman, M.A. (2018) Family Structure and Subsequent Anxiety Symptoms; Minorities' Diminished Return. Brain Sciences, 8, 97. https://doi.org/10.3390/brainsci8060097

[47] Assari, S. (2018) Blacks' Diminished Return of Education Attainment on Subjective Health; Mediating Effect of Income. Brain Sciences, 8, 176.

https://doi.org/10.3390/brainsci8090176

[48] Assari, S. and Caldwell, C.H. (2019) Family Income at Birth and Risk of Attention Deficit Hyperactivity Disorder at Age 15: Racial Differences. Children (Basel), 6, 10. https://doi.org/10.3390/children6010010

[49] Soneji, S., Knutzen, K.E., Tan, A.S.L., et al. (2019) Online Tobacco Marketing among US Adolescent Sexual, Gender, Racial, and Ethnic Minorities. Addictive Behaviors, 95, 189-196. https://doi.org/10.1016/j.addbeh.2019.03.015 